\title{
Contrast-Enhanced Ultrasonography in the Diagnosis of Upper Urinary Tract Urothelial Cell Carcinoma: A Preliminary Study
}

\author{
Diagnose des urothelialen Zellkarzinoms des oberen Harntraktes mittels \\ kontrastverstärkter Sonografie: eine Vorstudie
}

Authors

Affiliations
F. M. Drudi ${ }^{1}$, G. Di Candio ${ }^{2}$, N. Di Leo ${ }^{3}$, F. Malpassini ${ }^{4}$, M. Gnecchi ${ }^{4}$, V. Cantisani ${ }^{1}$, F. Iori $^{5}$, M. Liberatore ${ }^{6}$

Affiliation addresses are listed at the end of the article.
Key words
- CEUS
- upper urinary tract
- urothelial cell carcinoma
- ultrasound
- CT urography MR urography

received 27.7.2012

accepted $\quad 1.10 .2012$

Bibliography

DOI http://dx.doi.org/

10.1055/s-0032-1325548

Published online: November 19 , 2012

Ultraschall in Med 2013; 34 :

30-37 @ Georg Thieme Verlag KG Stuttgart · New York

ISSN 0172-4614

\section{Correspondence \\ Dr. Francesco M. Drudi}

Department of Radiology,

University La Sapienza

Viale Regina Elena 324

00161 Rome

Italy

Tel.: ++39/6/49978439

Fax: ++39/6/49 978438

francescom.drudi@uniroma1.it

\section{Zusammenfassung \\ V}

Ziel: Hauptziel: Die Bestimmung der Effektivität der kontrastverstärkten Sonografie (CEUS) im Vergleich mit der Multi-Detektor-Computertomografie-Urografie (MDCTU) und der Magnetresonanz-Urografie (MRU) bei der Diagnose von Malignomen des oberen Harntraktes. Sekundäre Ziele: Vergleich der durch CEUS, MDCTU und MRU gemessenen Tumorgröße und die Bewertung des Nutzens von CEUS bei der Unterscheidung von hoch- und niedriggradigen Tumoren.

Material und Methoden: In Zusammenhang mit dieser retrospektiven Studie, die von Januar 2009 bis September 2011 durchgeführt wurde, wurde bei 18 Patienten MDCTU oder MRU, GraustufenUltraschall (US), Farbdoppler-Sonografie und CEUS nach der Operation und eine histologischen Untersuchung der Präparats durchgeführt. Die quantitative Analyse wurde unter Verwendung einer Perfusionssoftware durchgeführt; Zeit-Intensitätskurven wurden extrahiert und folgende Parameter wurden berücksichtigt: Wash-in-Zeit, Zeit zur Spitze, maximale Signalintensität und Wash-out-Zeit.

Ergebnisse: Der Graustufenultraschall entdeckte 15/18 Läsionen, der Farbdoppler zeigte in 8 Läsionen kein Flusssignal, in 9 Läsionen niedrige Farbsignale und in einem Herd ein deutliches Farbsignal; CEUS erkannte 17/18 Herdbefunde, die nicht nachgewiesene Läsion war die Kleinste $(1,2 \mathrm{~cm})$ und befand sich im Nierenbeckenkelchsystem. Die semiquantitative Analyse führte zu unterschiedlichen Ergebnissen für hoch- und niedriggradige urotheliale Zellkarzinome (UCC). Alle nachgewiesenen Raumforderungen des oberen Harntraktes waren UCCs. MRU, MDCTU und der Graustufenultraschall überschätzten die Tumorgröße, während CEUS am genauesten war. Schlussfolgerung: CEUS ist für die Bewertung von Raumforderungen des oberen Harntraktes geeignet, da diese Methode eine Differenzierung

\section{Abstract \\ $\nabla$}

Purpose: The main objective was to assess the effectiveness of contrast-enhanced ultrasonography (CEUS) in the diagnosis of upper urinary tract malignancies by comparing with multidetector computed tomographic urography (MDCTU) and magnetic resonance urography (MRU). Secondary objectives were to compare the tumor size measured with CEUS, MDCTU and MRU and to assess the usefulness of CEUS in distinguishing highgrade tumors from low-grade ones.

Materials and Methods: In connection with this prospective study carried out from January 2009 to September 2011, 18 patients underwent MDCTU or MRU, grayscale ultrasonography (US), color Doppler ultrasonography and CEUS followed by surgery and histological examination of the specimen. Quantitative analysis was performed using perfusion software. Time intensity curves were extracted and the following parameters were considered: wash-in time, time-topeak, maximum signal intensity and wash-out time.

Results: Grayscale US identified 15/18 lesions; color Doppler showed no flow signal in 8 lesions, low color signal in 9 lesions and an intense color signal in 1 lesion; CEUS identified 17/18 lesions with the undetected lesion being the smallest one $(1.2 \mathrm{~cm})$ located in the upper pelvicalyceal system. Semi-quantitative analysis produced different data for high-grade and low-grade urothelial cell carcinoma (UCC). All detected upper urinary tract masses were UCCs. MRU, MDCTU and grayscale US overestimated the tumor size, while CEUS was the most accurate.

Conclusion: CEUS is useful for evaluating upper urinary tract masses as this method permits differentiation between high-grade and low-grade tumors as well as distinction of the tumor from the adjacent structures and accurate mass measurements. 
von hoch- und niedriggradigen Tumoren sowie die Abgrenzung des Tumors von den umgebenden Strukturen und eine exakte Größenbestimmung der Raumforderung ermöglicht.

\section{Introduction}

Upper urinary tract malignancies are relatively rare and account for only $5 \%$ of urothelial cell carcinomas (UCCs) [1, 2]. Most upper urinary tract UCCs (75\%) are located in the renal pelvis and calyces, while the remaining $25 \%$ are located in the ureter: $70 \%$ in the distal ureter, $25 \%$ in the mid-ureter and $5 \%$ in the proximal ureter [3].

Multidetector computed tomographic urography (MDCTU) and magnetic resonance urography (MRU) are widely considered to be the best available modalities for the diagnosis and staging of urothelial carcinoma [4-10]. The sensitivity (MDCTU 92.9100\%; MRU 62.9-94.1\%) and specificity (MDCTU 93-100\%; MRU $81-100 \%$ ) of these methods are high but diagnosis is often based on the presence of indirect signs, such as wall thickening and hydroureteronephrosis, rather than on the actual recognition of the lesion.

Ultrasound (US) is the first-line imaging modality in patients with hematuria [2], as color Doppler US is useful in urological imaging and power Doppler US improves the sensitivity in the detection of slow blood flow [11].

The introduction of contrast-enhanced US (CEUS) has made it possible to detect and image blood flow in small vessels using microbubbles to assess regional microvascular perfusion in tissues such as the liver, kidney and myocardium [12]. The advantage of this method compared to MDCTU and MRU lies in the ability to provide real-time images of blood flow within the lesions.

The main objective of this study was to assess the effectiveness of CEUS in the diagnosis of upper urinary tract neoplasms compared to MDCTU and MRU which are considered to be the gold standard. Secondary objectives were to assess the usefulness of CEUS in distinguishing high-grade tumors from low-grade ones on the basis of time-intensity curves and also to compare the tumor size measured with CEUS, MDCTU and MRU.

\section{Materials and methods}

$\nabla$

\section{Patient population}

From January 2009 to September 2011, 18 patients, 10 males and 8 females (mean age: 74 ; range: $62-85$ ), were referred to diagnostic investigation with suspicion of upper urinary tract carcinoma due to persistent gross hematuria $(n=11)$ or microscopic hematuria $(n=7)$, positive or atypical urine cytology results but no abnormalities at cystoscopy ( $\bullet$ Tab. 1 ).

Written informed consent was obtained from all patients, and the procedures were in accordance with the ethical standards of the Committee on Human Experimentation of this institution.

\section{Imaging techniques}

Investigational protocol

All patients underwent MDCTU or MRU to assess the presence of a neoplastic lesion. They subsequently underwent grayscale US, color Doppler (CDUS) and CEUS during the same session. The same radiologists performed US, color Doppler and CEUS; they were aware of the MDCTU and MRU findings.
All patients underwent surgery (nephroureterectomy with bladder cuff excision). The dimensions of the surgical specimen were recorded before it was submitted to histological examination which confirmed UCC in all cases.

\section{MDCTU}

Thirteen patients underwent MDCTU, which was performed on 64-MDCT scanners (Siemens, Erlangen, Germany) using a threephase protocol. $400-500 \mathrm{ml}$ of water were administered orally to the patients 20 minutes before the examination. Unenhanced CT scans of the abdomen and pelvis were obtained. Nephrographic phase images were then obtained 80 sec after bolus injection ( $2 \mathrm{ml} / \mathrm{kg}$ body weight) of iohexol (Omnipaque 300, GE Healthcare, USA) or iomeprolo (Iomeron 350, Bracco, Italy). Excretory phase images of the abdomen and pelvis were obtained 8 minutes after injection of the contrast agents. Unenhanced and nephrographic phase scans were reconstructed with sections with a thickness of $2-5 \mathrm{~mm}$. The excretory phase scan was reconstructed as sections with a thickness of $1.25 \mathrm{~mm}$.

\section{MRU}

Five patients underwent MRU, which was performed on $1.5 \mathrm{~T}$ (Siemens) scanners. Multisequence MRI was carried out including T1-weighted and T2-weighted sequences (slice thickness: 6.6-7.7 mm). Diffusion-weighted imaging (DWI) was carried out with single-shot spin-echo planar imaging sequences (slice thickness: 6-7 mm). Spectral attenuated inversion recovery (SPAIR) fat suppression was performed under free-breathing acquisition. In the dynamic contrast-enhanced (DCE) MRI sequences, 24 slices were sequentially acquired 30,80 , and $180 \mathrm{sec}$ after administration of meglumine gadopentetate $(0.1 \mathrm{ml} / \mathrm{kg}$ body weight).

\section{US and CDUS}

All patients underwent grayscale US and CDUS. US examination was performed on Aplio (Toshiba, Tokyo, Japan), MyLab and MyLab-Twice (Esaote, Genoa, Italy) using a 3.5-5 MHz multifrequency broadband convex transducer. Examination was performed when the urinary bladder was adequately full to visualize the possible presence of lesions in the ureteral-bladder junction. The location and size of the lesions detected during grayscale US were recorded. CDUS was performed using scanning parameters set for maximum sensitivity for slow flow while the power output was increased to maximum. Color gain was increased to the point just before the appearance of random noise. The pulse repetition frequency was set at the lowest possible level. The images were assigned the following scores: 0 = no color signal, $1=$ low color signal, 2 = intense color signal.

\section{CEUS}

In the same session all patients underwent real-time continuous examination using a low mechanical index (range: 0.04-0.1) after the administration of SonoVue $\left(\mathrm{Bracco}^{\mathrm{TM}}\right)$. SonoVue is a blood pool US contrast agent comprising microbubbles. A total of $4.8 \mathrm{ml}$ was administered in 2 intravenous bolus doses of 2.4 $\mathrm{ml}$; the second dose was injected 15 minutes after the first and 


\begin{tabular}{|c|c|c|c|c|c|c|c|}
\hline & age & sex & location & symptoms & $\begin{array}{l}\text { specimen length } \\
\text { (cm) }\end{array}$ & urine cytology & grading \\
\hline 1 & 81 & M & DU & $\begin{array}{l}\text { Gross } \\
\text { Hematuria }\end{array}$ & 2.3 & $P$ & UCC-HG \\
\hline 2 & 72 & M & DU & $\begin{array}{l}\text { Gross } \\
\text { Hematuria }\end{array}$ & 2.7 & $P$ & UCC-HG \\
\hline 3 & 69 & M & PU & $\begin{array}{l}\text { Gross } \\
\text { Hematuria, } \\
\text { Flank Pain }\end{array}$ & 3.2 & $P$ & UCC-LG \\
\hline 4 & 63 & $\mathrm{~F}$ & C & $\begin{array}{l}\text { Microscopic } \\
\text { Hematuria }\end{array}$ & 1.2 & $P$ & UCC-HG \\
\hline 5 & 75 & $\mathrm{~F}$ & DU & $\begin{array}{l}\text { Microscopic } \\
\text { Hematuria }\end{array}$ & 2.4 & A & UCC-LG \\
\hline 6 & 74 & M & $\mathrm{MU}$ & $\begin{array}{l}\text { Gross } \\
\text { Hematuria }\end{array}$ & 1.9 & $P$ & UCC-LG \\
\hline 7 & 81 & M & DU & $\begin{array}{l}\text { Microscopic } \\
\text { Hematuria }\end{array}$ & 2.5 & $P$ & UCC-HG \\
\hline 8 & 79 & $\mathrm{~F}$ & DU & $\begin{array}{l}\text { Gross } \\
\text { Hematuria }\end{array}$ & 3.1 & $P$ & UCC-LG \\
\hline 9 & 84 & $\mathrm{~F}$ & PU & $\begin{array}{l}\text { Gross } \\
\text { Hematuria }\end{array}$ & 3.8 & $P$ & UCC-LG \\
\hline 10 & 70 & M & $\mathrm{MU}$ & $\begin{array}{l}\text { Microscopic } \\
\text { Hematuria }\end{array}$ & 2.1 & A & UCC-LG \\
\hline 11 & 68 & $\mathrm{~F}$ & DU & $\begin{array}{l}\text { Microscopic } \\
\text { Hematuria }\end{array}$ & 2.5 & $P$ & UCC-HG \\
\hline 12 & 72 & M & PU & $\begin{array}{l}\text { Gross } \\
\text { Hematuria }\end{array}$ & 4.1 & A & UCC-LG \\
\hline 13 & 70 & M & DU & $\begin{array}{l}\text { Gross } \\
\text { Hematuria } \\
\text { Flank Pain }\end{array}$ & 3.9 & $P$ & UCC-LG \\
\hline 14 & 73 & $\mathrm{~F}$ & $\mathrm{MU}$ & $\begin{array}{l}\text { Gross } \\
\text { Hematuria }\end{array}$ & 2.5 & A & UCC-LG \\
\hline 15 & 85 & M & MU & $\begin{array}{l}\text { Microscopic } \\
\text { Hematuria }\end{array}$ & 7.1 & $\mathrm{P}$ & UCC-HG \\
\hline 16 & 62 & M & DU & $\begin{array}{l}\text { Microscopic } \\
\text { Hematuria }\end{array}$ & 3.5 & $P$ & UCC-LG \\
\hline 17 & 79 & $\mathrm{~F}$ & DU & $\begin{array}{l}\text { Gross } \\
\text { Hematuria }\end{array}$ & 4.3 & P & UCC-HG \\
\hline 18 & 73 & $\mathrm{~F}$ & C & $\begin{array}{l}\text { Gross } \\
\text { Hematuria }\end{array}$ & 3.3 & A & UCC-LG \\
\hline
\end{tabular}

${ }^{1}$ M: male, F: female, DU: distal ureter, MU: mid ureter, PU: proximal ureter, C: pielo-calyceal system, P: positive, A: atypical, UCC: urothelial cell carcinoma, HG: high grade, LG: low grade.

both were followed by $5 \mathrm{ml}$ of a saline flush. The second injection was performed to evaluate the contralateral urinary tract.

Still images of the entire examination were digitally recorded on magnetic optical disk. Recording was initiated at the start of the first contrast injection and at the start of the second injection. All time measurements started at these points, which were "time-0" in all recorded video clips.

The images were analyzed off-site at consensus conferences to determine the size of the lesion, baseline and CDUS appearance as well as the signal intensity of the enhancement after SonoVue administration.

The images were interpreted by the two radiologists who performed the examination. Both were skilled in urologic US and had more than 5 years of CEUS examination experience.

Perfusion software was then used to estimate the perfusion pattern (Qontrast v 3.0, Bracco, Milan, Italy) [13]. This quantitative software analyzes the temporal sequence of the images. Time-intensity curves (TIC) were extracted from regions of interest in the lesion, and TIC quantitative analysis was performed. The following parameters were considered: wash-in time, time-to-peak (TTP), maximum signal intensity (SI) and wash-out time. The sig- nal intensity was calculated for every pixel for every second, thus generating maps of perfusion parameters.

\section{Statistical analysis}

The paired T-test was performed to evaluate the statistical significance of the measurements obtained using the four imaging techniques. The measurements were compared to the actual length of the lesion measured on the surgical specimen.

\section{Results}

MRU and MDCTU identified upper urinary tract masses in all 18 patients, who subsequently underwent CEUS. Histological examination after surgery confirmed UCC in all patients. The lesions were located as follows: $9(50 \%)$ in the distal ureter; $4(22.2 \%)$ in the mid-ureter; $3(16.6 \%)$ in the proximal ureter; $2(11.2 \%)$ in the pelvicalyceal system. The mean dimension was $3.1 \mathrm{~cm}$ (range $1.2-7.1 \mathrm{~cm}$ ).

In MDCTU and MRU, 18 lesions exhibited enhancement. In the urographic phase, the lesions did not exhibit direct enhance- 
Tab. 2 Urothelial lesions; length $(\mathrm{cm})$.

\begin{tabular}{|llll|}
\hline US & MDCTU|MRU & CEUS & specimen \\
\hline 2.8 & 2.7 & 2.4 & 2.3 \\
\hline 3.3 & 3.2 & 2.8 & 2.7 \\
\hline 4.0 & 3.7 & 3.4 & 3.2 \\
\hline unidentified & 1.4 & unidentified & 1.2 \\
\hline 3.0 & 2.8 & 2.5 & 2.4 \\
\hline 2.4 & 2.3 & 2.0 & 1.9 \\
\hline 3.1 & 2.8 & 2.6 & 2.5 \\
\hline 3.9 & 3.5 & 3.2 & 3.1 \\
\hline 4.8 & 4.4 & 4.0 & 3.8 \\
\hline unidentified & 2.4 & 2.2 & 2.1 \\
\hline 3.1 & 3.0 & 2.6 & 2.5 \\
\hline 5.0 & 4.8 & 4.3 & 4.1 \\
\hline 4.8 & 4.6 & 4.1 & 3.9 \\
\hline unidentified & 2.9 & 2.6 & 2.5 \\
\hline 8.1 & 7.9 & 7.3 & 7.1 \\
\hline 4.4 & 4.0 & 3.7 & 3.5 \\
\hline 5.2 & 5.0 & 4.5 & 4.3 \\
\hline 4.3 & 3.8 & 3.5 & 3.3 \\
\hline
\end{tabular}

Tab. 3 HG-UCC e LG-UCC in bladder and upper urinary tract (UUT).

\begin{tabular}{lllll|} 
& HG-UCC & \multicolumn{3}{l}{ LG-UCC } \\
\cline { 2 - 5 } & Bladder & UUT & Bladder & UUT \\
\hline $\begin{array}{l}\text { wash-in } \\
\text { time }\end{array}$ & $13 \mathrm{sec}$ & $13-18 \mathrm{sec}$ & $10 \mathrm{sec}$ & $10 \mathrm{sec}$ \\
\hline TTP & $>28 \mathrm{sec}$ & $>30 \mathrm{sec}$ & $<26 \mathrm{sec}$ & $<25 \mathrm{sec}$ \\
\hline SI & $>50 \%$ & $>55 \%$ & $<50 \%$ & $<50 \%$ \\
\hline $\begin{array}{l}\text { wash- } \\
\text { out time }\end{array}$ & $58 \mathrm{sec}$ & $>80 \mathrm{sec}$ & $<50 \mathrm{sec}$ & $<50 \mathrm{sec}$ \\
\hline
\end{tabular}

ment, and the diagnosis of upper urinary tract neoplasm was made on the basis of indirect indicators. The lesion size measured on MDCTU and MRU images was found to be $15-20 \%$ greater than the actual size of the surgical specimen.

Grayscale US identified 15 out of 18 lesions (83.3\%). One lesion in the upper pelvicalyceal system and 2 in the mid-ureter were not identified. The lesion size measured on grayscale US images was found to be about $25 \%$ greater than the actual size of the surgical specimen.

In CDUS the 15 lesions presented different color signals: 7 lesions exhibited no flow signal (score 0 ); 7 presented low color signal (score 1); 1 exhibited intense color signal (score 2).

In CEUS 17 patients were found positive for upper urinary tract neoplasm, while 1 was found negative. The undetected lesion was small $(1.2 \mathrm{~cm})$ and located in the upper pelvicalyceal system of the kidney. It was not identified with grayscale US. CEUS examination therefore resulted in 17 true-positive cases and 1 falsenegative case, yielding a sensitivity of $94.4 \%$.

The lesion size measured on the CEUS images came close to the actual dimensions of the surgical specimen ( $\bullet$ Tab. 2). In CEUS all detected lesions exhibited homogeneous enhancement in every part of the lesion.

The paired T-test results were: US vs. specimen $\mathrm{P}>0.50$; MDCTU/ MRU vs. specimen $\mathrm{P}>0.50$; CEUS vs. specimen $\mathrm{P}<0.05$.

TIC and semi-quantitative analysis produced the following results: high-grade UCCs: wash-in after $13-18 \mathrm{sec}$, TTP > $30 \mathrm{sec}$, SI $>55 \%$, wash-out time $>80$ secs; low-grade UCCs: wash-in time $10 \mathrm{sec}$, TTP $<25 \mathrm{sec}, \mathrm{SI}<50 \%$, wash-out time $<50 \mathrm{sec}(\bullet$ Tab. 3 ) [2].
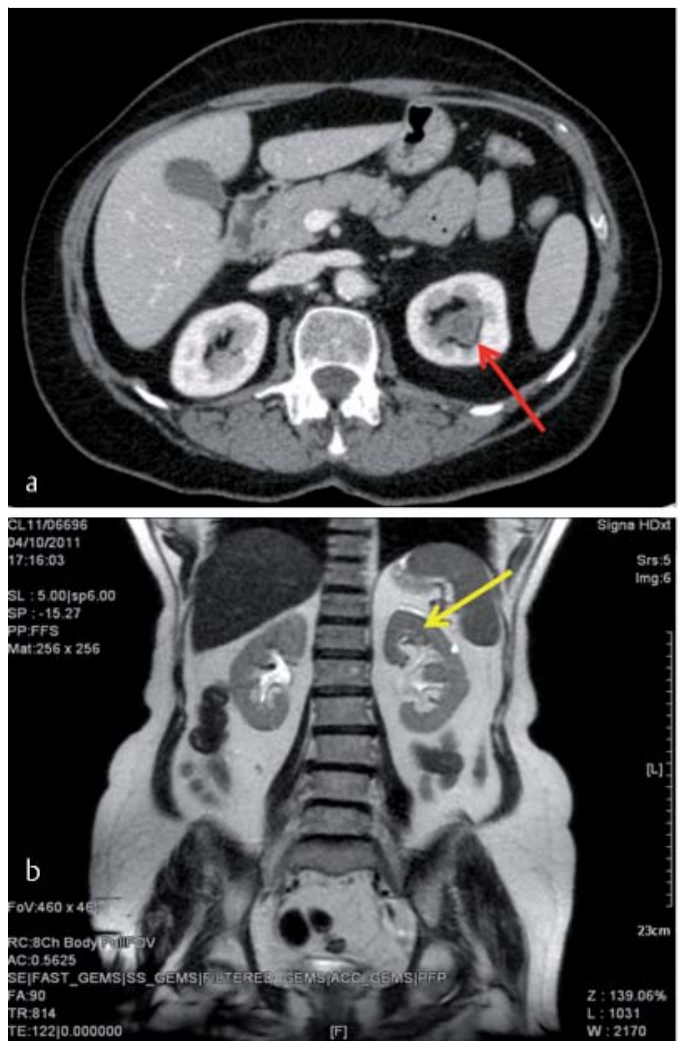

Fig. 1 A 63-year-old woman with high-grade UCC located in the upper pelvicalyceal group of the left kidney: a MDCTU shows a small mass in the calyceal cavity of the upper pole (red arrow); b MRU confirms the presence of the lesion (yellow arrow); c CDUS does not show the lesion, normal vascularity of the renal parenchyma; d US (left: gray-scale; right: CEUS): the lesion is not identified; e Surgical specimen: lesion length $12 \mathrm{~mm}$ (black arrow).

Abb. 1 Eine 63-jährige Frau mit hochgradigem UCC, welches im oberen Nierenbeckenkelchsystems der linken Niere lokalisiert ist: a MDCTU zeigt eine kleine Raumforderung im Kelchraum des oberen Pols (roter Pfeil); b MRU bestätigt den Herdbefund (gelber Pfeil); c CDUS zeigt keine Läsion, normale Vaskularität des Nierenparenchyms; $\mathbf{d}$ US (links: B-Bild, rechts: CEUS): die Läsion wird nicht erkannt; e Operationspräparat: Länge des Herdes $12 \mathrm{~mm}$ (schwarzer Pfeil).

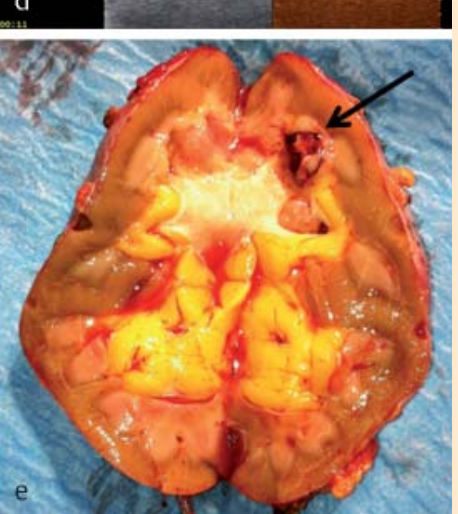



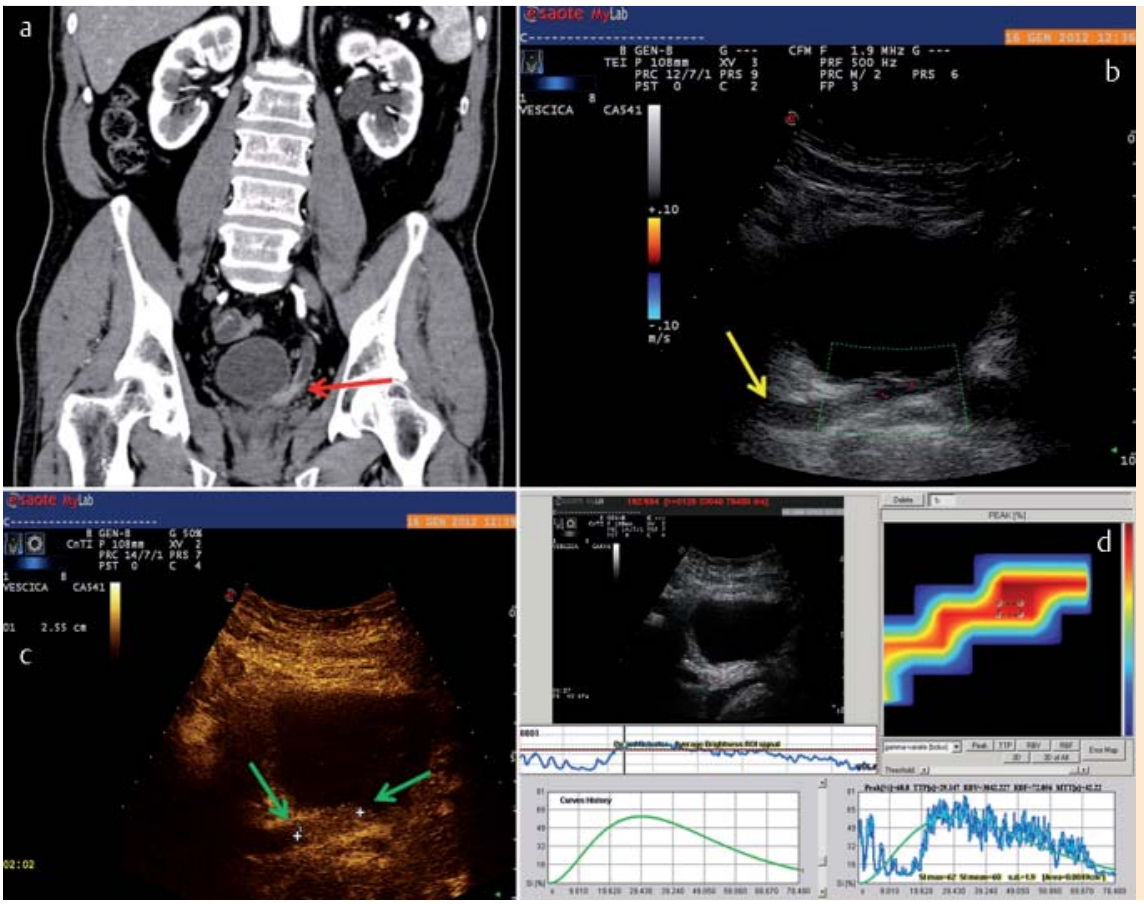

Fig. 2 An 81-year-old man with high-grade UCC located in the left distal ureter: a MDCTU shows moderate hydroureteronephrosis of the urinary tract, the lesion is moderately enhanced (red arrow); $\mathbf{b}$ CDUS: the lesion is poorly vascularized (score 1) and the margins are blurred due to the presence of intraluminal artifacts (yellow arrow) (length $38 \mathrm{~mm}$ ); c CEUS: average late-phase enhancement of the lesion (length $25 \mathrm{~mm}$ ) (green arrows); $\mathbf{d}$ TIC showing the following values: washin time $13 \mathrm{sec}$, TTP $29 \mathrm{sec}, \mathrm{SI}>60$ and wash-out time $>80$ sec suggesting high-grade UCC.

Abb.2 Ein 81-jähriger Mann mit hochgradigem UCC in der linken distalen Harnröhre: a MDCTU zeigt eine moderate Hydroureteronephrose des Harntraktes; die Läsion ist mäßig verstärkt (roter Pfeil); b CDUS: die Läsion ist schlecht vaskularisiert (Grad 1) und die Ränder sind aufgrund intraluminaler Artefakte verschwommen (gelber Pfeil) (Länge $38 \mathrm{~mm}$ ); c CEUS: durchschnittliche Signalverstärkung der Läsion in der Spätphase (Länge $25 \mathrm{~mm}$ ) (grüne Pfeile); $\mathbf{d}$ TIC zeigt folgende Werte: Wash-inZeit 13 s, TTP 29 s, SI > 60 und Wash-out-Zeit $>80$ s, was für ein hochgradiges UCC spricht.
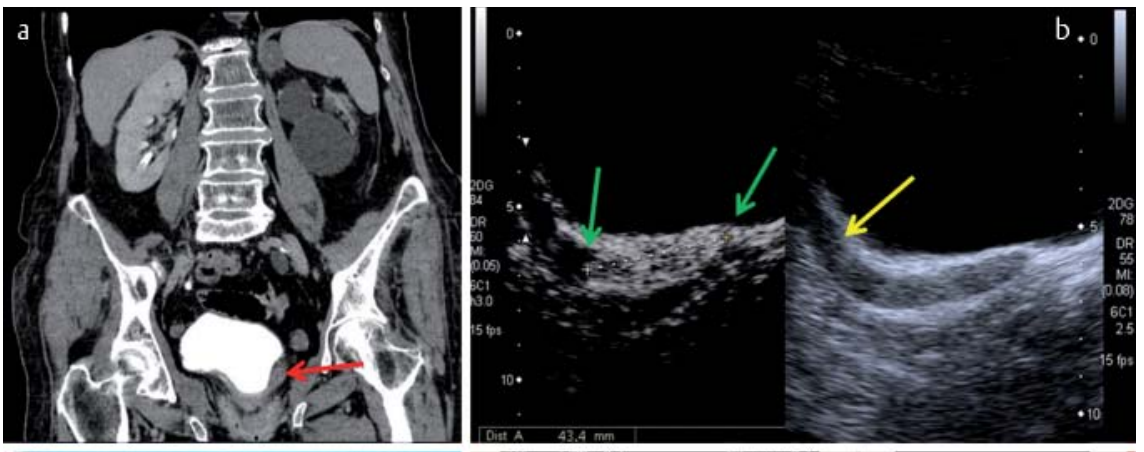
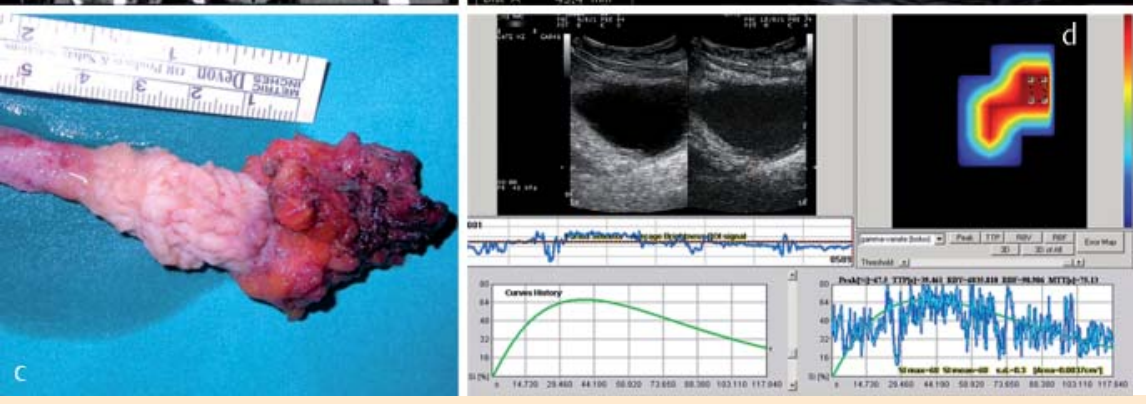

Fig. 3 A 79-year-old woman with high-grade UCC located in the left distal ureter: a MDCTU shows left-sided hydroureteronephrosis and thickening of the distal ureter with poor enhancement (red arrow); b US (left: CEUS; right: gray-scale) intense enhancement of the lesion (green arrows) (length $43 \mathrm{~mm}$ ), in the right image, intraluminal artifacts (yellow arrow) do not permit an accurate measurement; $c$ Surgical specimen, lesion length measured on the specimen corresponds to measurement made at CEUS; d TIC showing the following values: wash-in time 14 seconds, TTP $35 \mathrm{sec}$, $\mathrm{SI}>64$ and wash-out time $>80 \mathrm{sec}$ suggesting high-grade UCC.

\section{Discussion}

$\nabla$

MDCTU and MRU are the gold standard for imaging of the upper urinary tract and have replaced intravenous excretory urography
Abb.3 Eine 79-jährige Frau mit hochgradigem UCC in der linken distalen Harnröhre: a MDCTU zeigt eine linksseitige Hydrourethernephrose und eine Verdickung des distalen Urethers mit geringer Signalverstärkung (roter Pfeil); b im US (links: CEUS, rechts: B-Bild) hochgradige Signalverstärkung der Läsion (grüne Pfeile) (Länge $43 \mathrm{~mm}$ ), in der rechten Abbildung, die intraluminalen Artefakte (gelber Pfeil) lassen keine genaue Messung zu; c Operationspräparat: die am Präparat gemessene Größe der Läsion entspricht der Messung mittels CEUS; d TIC zeigt folgende Werte: Wash-inZeit 14 s, TTP 35 s, SI >64 und Wash-out-Zeit > 80 s, was für ein hochgradiges UCC spricht.

[14-16]. Analysis of the data available in the literature shows that the sensitivity and specificity of MDCTU are close to $100 \%$ with a greater sensitivity and specificity in lesions located in the renal pelvis (100\%) than in the ureter $(92.9 \%)$ [1, $16-18]$. 

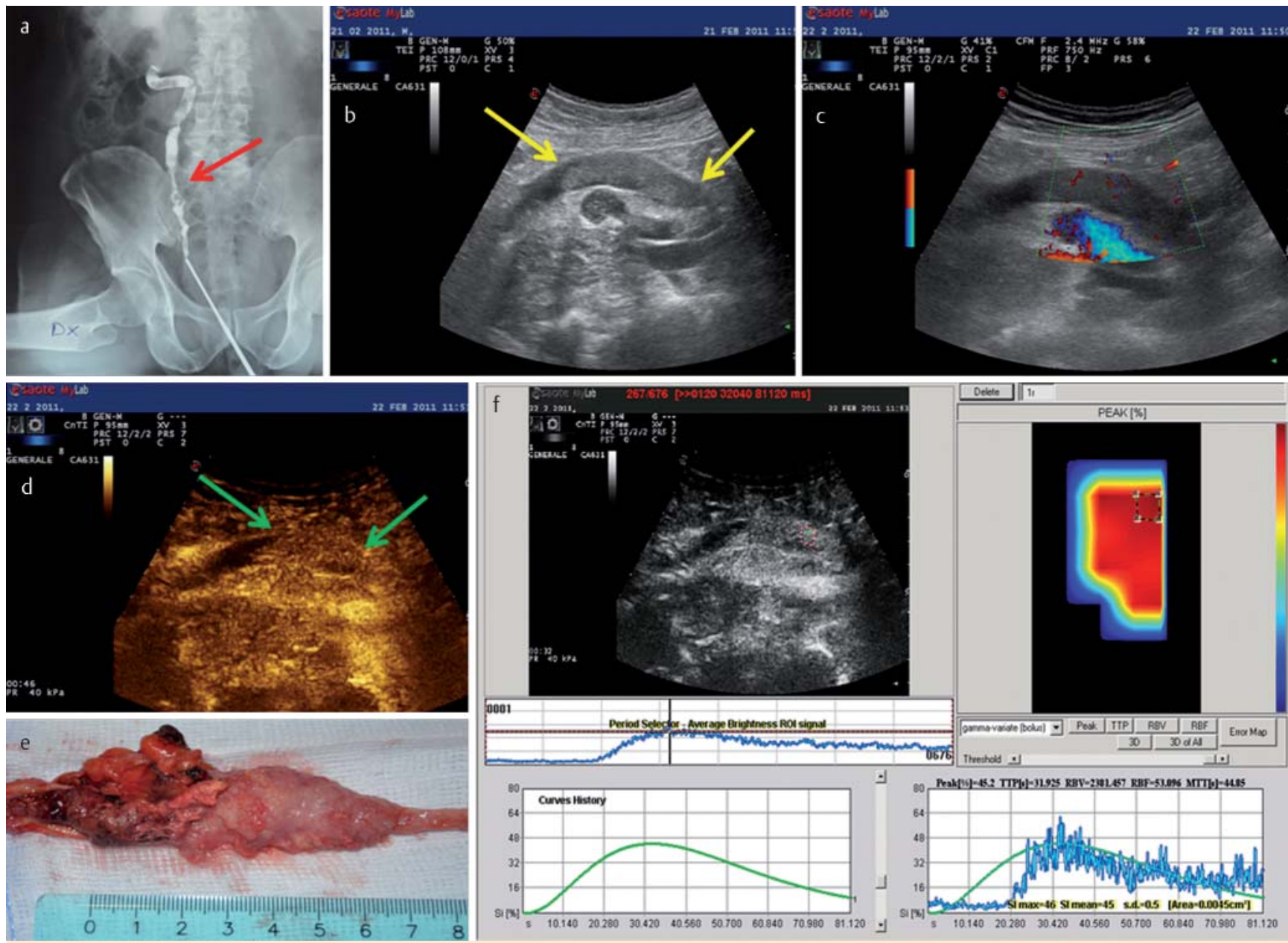

Fig. 4 An 85-year-old man with high-grade UCC located in the right mid ureter: a Retrograde pyelography shows filling defect of the ureter (red arrow); $\mathbf{b}$ Gray-scale US shows a solid mass in the lumen of the right ureter (yellow arrows), the iliac artery and vein are visible below; c CDUS shows poor vascular signal within the lesion (score 1); d CEUS shows homogeneous enhancement of the neoplastic lesion (green arrows) (length $70 \mathrm{~mm}$ ); e Surgical specimen: lesion length is $71 \mathrm{~mm}$; $\mathbf{f ~ T I C ~ s h o w i n g ~ t h e ~}$ following values: wash-in time $13 \mathrm{sec}$, TTP $31 \mathrm{sec}$, SI 44 and washout time $>80$ sec suggesting high-grade UCC.

Abb. 4 Ein 85-jähriger Mann mit hochgradigem UCC in der rechten mittleren Harnröhre: a Die retrograde Pyelografie zeigt die Füllung des Harnleiters (roter Pfeil); $\mathbf{b}$ das B-Bild zeigt eine kompakte Raumforderung im Lumen des rechten Urethers (gelbe Pfeile), die Arterie und Vene des Beckens sind darunter sichtbar; c CDUS zeigt ein schlechtes vaskuläres Signal innerhalb der Läsion (Grad 1); d CEUS zeigt eine homogene Signalverstärkung der neoplastischen Läsion (grüne Pfeile) (Länge $70 \mathrm{~mm}$ ); e Operationspräparat: Die Länge der Läsion beträgt $71 \mathrm{~mm}$; f TIC zeigt die folgenden Werte: Wash-in-Zeit 13 s, TTP 31 s, SI 44 und Wash-out-Zeit $>80$ s spricht für ein hochgradiges UCC.

In the literature, the two most common sequences in MRU are T2-weighted hydrographic sequences without contrast agent and T1-spoiled gradient-recalled echo (GRE) sequences during the excretory phase after gadolinium administration $[19,20]$ with a sensitivity of $62.9-76.5 \%$ and a specificity of $89-100 \%$ $[20,21]$. The use of DWI sequences substantially increases the sensitivity to up to $94.1 \%$, as compared to $\mathrm{T} 1$ and $\mathrm{T} 2$ sequences $[9,10]$.

In the present study, 18/18 lesions exhibited enhancement in MDCTU and MRU. During the urographic phase the lesions were diagnosed on the basis of other indicators such as thickening of the ureter wall or pelvicalyceal system as well as filling defects which were particularly evident in the 7 cases $(38.8 \%$ ) affected by hydroureteronephrosis [17, 20, 22].

In grayscale US, UCC of the renal pelvis typically appears as a solid mass which is difficult to distinguish from the renal sinus, particularly in the absence of hydronephrosis [23-25]. US has a limited role in the evaluation of UCC of the ureter as the ureter is rarely visualized in its entirety, even if dilated. When visualized, these tumors are typically intraluminal soft-tissue masses with proximal distention of the ureter.

In the present study, grayscale US identified 15 lesions, while 3 were not identified. Two of the unidentified lesions were located in the mid-ureter and there was mild dilation of the ureter. The third undetected lesion was the smallest $(1.2 \mathrm{~cm})$ and was located in the upper pelvicalyceal system.

The use of color Doppler did not significantly increase US sensitivity owing to the frequent absence of a vascular signal within the neoplastic lesion: 7 lesions out of 18 (38.8\%) were assigned a score of 0 .

In CEUS, 17 lesions out of 18 (94.4\%) exhibited enhancement offering direct visualization of the lesion. The lesion that was not detected in CEUS was located in the upper pelvicalyceal system of the kidney and was not identified in grayscale US ( $\bullet$ Fig. 1 ). It probably went undetected because of the intense enhancement of the renal parenchyma which masked the enhancement of the 
lesion. TTP of the renal parenchyma occurred about $18 \mathrm{sec}$ after the first injection of contrast agent and wash-out took more than 5 min thereby completely masking the lesion. In the present patient population, CEUS identified another lesion located in the calyceal cavity as it was larger and caused swelling of the renal pelvis. This may indicate a greater sensitivity of CEUS in masses located in the ureter (16 out of 16 lesions were identified; sensitivity $100 \%$ ) than in smaller lesions located in the calyceal system ( 1 out of 2 lesions was identified; sensitivity $50 \%$ ). The overall sensitivity of CEUS was $94.4 \%$. Because of the lack of false-positive and true-negative patients, the sensitivity was the only statistical datum that could be extrapolated about CEUS in the detection of upper urinary tract UCCs.

MDCTU and MRU overestimated tumor size by $15-20 \%$. This phenomenon is probably due to the fact that it is difficult to differentiate between the lesion and the ureteral walls or the calyceal walls because of concurrent enhancement of the lesion and the surrounding wall with no neoplasm [26].

Grayscale US also overestimated tumor size by about $25 \%$. In most cases this phenomenon is linked to the presence of intraluminal echoes due to artifacts, cellular debris and/or blood clots. CEUS yielded tumor sizes close to the actual dimensions of the surgical specimens as amplitude subtraction permitted the suppression of intraluminal echoes caused by artifacts ( $\bullet$ Fig. 2, 3). Agreement between the actual tumor size of the surgical specimen and the size measured in CEUS shows that areas exhibiting enhancement in CEUS are actually neoplastic lesions.

The fact that CEUS showed a vascular signal from the lesion in an elevated percentage of cases, i.e., higher than CDUS and close to MDCTU/MRU (CEUS 94\%; CDUS 61\%; MDCTU/MRU 100\% of cases), may be attributed to the ability of the US blood pool contrast agent to provide real-time depiction of the lesion vascularity.

The clips obtained in CEUS were used for the construction of TICs for the comparison between enhancement patterns of highgrade and low-grade UCCs. This semi-quantitative analysis was compared to data obtained from studies of the bladder [27, 28]. Semi-quantitative analysis of high-grade and low-grade UCCs of the urinary tract yielded results similar to those related to bladder cancer.

The only contrasting data with regard to the signal intensity of high-grade UCCs was a case in which the lesion was located in the mid-ureter in close proximity to the iliac artery. In this case the SI was lower than the SI observed in the other cases. The close proximity of the iliac artery, where there were high concentrations of contrast agent, may have altered the SI measurement of the neoplastic lesion ( $\bullet$ Fig. 4).

The limitations of this study are related to the patient population. The first limitation is the low number of patients which is partly due to the relative rarity of upper urinary tract UCCs. Only 5 $10 \%$ of UCCs affect the upper urinary tract, while the remaining $90-95 \%$ are located in the bladder [2]. The second limitation is related to the selection criteria, as all the recruited patients already had a MDCTU and/or MRU report positive for the presence of an upper urinary tract lesion and urinary cytology positive for malignant cells. However, this was needed to assess the reliability of CEUS in the detection of upper urinary tract UCCs.

\section{Conclusions}

\section{$\nabla$}

The results of this study show that CEUS is a useful tool for evaluating upper urinary tract tumors as nearly all lesions were detected. CEUS allows a semi-quantitative analysis for differentiating the degree of malignancy, an accurate measurement of the mass by image subtraction, thus avoiding artifacts, and distinction of the tumor from adjacent structures based on enhancement timing.

CEUS may become a first-line examination in the diagnosis of upper urinary tract masses because of the short execution time and relatively low cost and thereby become an alternative to MRU and MDCTU in patients who are allergic to contrast agents or are affected by renal failure. However, further studies involving larger patient populations are mandatory to confirm these encouraging preliminary results.

\section{Affiliations \\ Department of Radiology, University La Sapienza, Rom \\ 2 Dipartimento Traslazionale, University of Pisa \\ 3 Departement of Radiology, “Sapienza”, Univ. of Rome \\ 4 Radiology, University La Sapienza, Rom \\ 5 Department of Urology, University “La Sapienza”, Rom \\ 6 Department of Nuclear Medicine, University “La Sapienza”, Rom}

\section{References}

1 Kupershmidt M, Margolis M, Jang HJ et al. Evaluation of upper urinary tract tumors with portal venous phase MDCT: a case-control study. Am J Roentgenol 2011; 197: 424-428

2 Rouprêt M, Zigeuner R, Palou J et al. Guidelines on upper urinary tract urothelial cell carcinomas. Eur Urol 2011; 59: 584-594

3 Margulis V, Shariat SF, Matin SF et al. Outcomes of radical nephroureterectomy: a series from the Upper Tract Urothelial Carcinoma Collaboration. Cancer 2009; 115: 1224-1233

4 Millán-Rodríguez F, Chéchile-Toniolo G, Salvador-Bayarri J et al. Upper urinary tract tumours after primary superficial bladder tumours: prognostic factors and risk groups. J Urol 2000; 164: 1183-1187

5 Meissner C, Giannarini G, Schumacher MC et al. The efficiency of excretory urography to detect upper urinary tract tumors after cystectomy for urothelial cancer. J Urol 2007; 178: 2287-2290

6 O'Malley ME, Hahn PF, Yoder IC et al. Comparison of excretory phase, helical computed tomography with intravenous urography in patients with painless haematuria. Clin Radiol 2003; 58: 294

7 Caoili EM, Cohan RH, Korobkin M et al. Urinary tract abnormalities: initial experience with multidetector-row CT urography. Radiology 2002; 222: 353-360

8 Leyendecker JR, Barnes CE, Zagoria RJ. MR urography: techniques and clinical applications. Radiographics 2008; 28: 23

9 Nishizawa S, Imai S, Okaneya T et al. Diffusion Weighted Imaging in the Detection of Upper Urinary Tract Urothelial Tumors. International Braz J Urol 2010; 36: $18-28$

10 Yoshida S, Masuda H, Ishii C et al. Usefulness of Diffusion-Weighted MRI in Diagnosis of Upper Urinary Tract Cancer. Am J Roentgenol 2011; 196: $110-116$

11 Bueschen AJ, Lockhart ME. Evolution of urological imaging. International Journal of Urology 2011; 18: 102-112

12 Fernandez CP, Ripolles T, Martinez MJ. Diagnosis of Acute Cortical Necrosis in Renal Transplantation by Contrast-Enhanced Ultrasound: a Preliminary Experience. Ultraschall in Med 2012, e-first

13 Dietrich CF, Averkiou MA, Correas J-M et al. An EFSUMB Introduction into Dynamic Contrast-Enhanced Ultrasound (DCE-US) for Quantification of Tumour Perfusion. Ultraschall in Med 2012; 33: 344-351

14 Dillman JR, Caoili EM, Cohan RH et al. Detection of upper tract urothelial neoplasms: sensitivity of axial, coronal reformatted, and curvedplanar reformatted image-types utilizing 16-row multi-detector CT urography. Abdom Imaging 2008; 33: 707-716

15 Wang LJ, Wong YC, Chuang CK et al. Diagnostic accuracy of transitional cell carcinoma on multidetector computerized tomography urography in patients with gross hematuria. J Urol 2009; 181: 524-531, discussion 531 
16 Wang $L J$, Wong YC, Huang CC et al. Multidetector computerized tomography urography is more accurate than excretory urography for diagnosing transitional cell carcinoma of the upper urinary tract in adults with hematuria. J Urol 2010; 183: 48 - 55

17 Jinzaki M, Matsumoto K, Kikuchi E et al. Comparison of CT Urography and Excretory Urography in the Detection and Localization of Urothelial Carcinoma of the Upper Urinary Tract. Am J Roentgenol 2011; 196: $1102-1109$

18 Cowan NC, Turney BW, Taylor NJ et al. Multidetector computed tomography urography for diagnosing upper urinary tract urothelial tumor. BJU Int 2007; 99: $1363-1370$

19 Takahashi N, Kawashima A, Glockner JF et al. Small (2-cm) upper-tract urothelial carcinoma: evaluation with gadolinium-enhanced three-dimensional spoiled gradient-recalled echo MR urography. Radiology 2008; 247: 451

20 Takahashi N, Glockner JF, Hartman RP et al. Gadolinium Enhanced Magnetic Resonance Urography for Upper Urinary Tract Malignancy. J Urol 2010; 183: $1330-1336$

21 Lee KS, Zeikus E, DeWolf WC et al. MR urography versus retrograde pyelography/ureteroscopy for the exclusion of upper urinary tract malignancy. Clinical Radiology 2010; 65: 185-192
22 Sadow CA, Wheeler SC, Kim J et al. Positive predictive value of CT urography in the evaluation of upper tract urothelial cancer. Am J Roentgenol 2010; 195: 337-343

23 Ingram MD, Sooriakumaran P, Palfrey $E$ et al. Evaluation of the upper urinary tract using transureteric ultrasound a review of the technique and typical imaging appearances. Clinical Radiology 2008; 63: 1026 1034

24 Joffe SA, Servaes S, Okon S et al. Multi-detector row CT urography in the evaluation of hematuria. RadioGraphics 2003; 23: 1441-1455

25 Kirkali Z, Tuzel E. Transitional cell carcinoma of the ureter and renal pelvis. Crit Rev Oncol Hematol 2003; 47: 155-169

26 Valignat C, Marechal JM, Rouviere $O$ et al. Contribution of computed tomography in the staging of upper urinary tract urothelial tumors. Importance of the tumor diameter measurement. Prog Urol 1997; 7: $217-224$

27 Drudi FM, Cantisani V, Liberatore $M$ et al. Role of low-mechanical index CEUS in the differentiation between low and high grade bladder carcinoma: a pilot study. Ultraschall in Med 2010; 31: 589-595

28 Piscaglia F, Nolsøe C, Dietrich CF et al. The EFSUMB Guidelines and Recommendations on the Clinical Practice of Contrast Enhanced Ultrasound (CEUS): Update 2011 on non-hepatic applications. Ultraschall in Med 2012; 33: 33 - 59 